\title{
The Analysis of the Risks Faced by China's Social Endowment Insurance under the Background of Rapid Aging Population
}

\author{
Ying Zhang, Zongli Qiu \\ School of Management, Jinan University, Guangzhou, China \\ Email: greenfulpure@163.com
}

Received 30 March 2015; accepted 13 April 2015; published 15 April 2015

Copyright (C) 2015 by authors and Scientific Research Publishing Inc.

This work is licensed under the Creative Commons Attribution International License (CC BY). http://creativecommons.org/licenses/by/4.0/

(c) (i) Open Access

\begin{abstract}
With the increasing aging population, the pressure of social endowment insurance in our country is growing more quickly than ever. Meanwhile, there are some practical problems and shortcomings in the current social endowment insurance system in China. And all this will raise risks in the field of inherent finance, fund investment and operation of the endowment insurance system. At the same time, it will cause new risks in the field of institution and policy. Thus, only by strengthening risk management and actively responding to the risks of social endowment insurance, can the government perfect the social endowment insurance system constantly.
\end{abstract}

\section{Keywords}

Aging Population, Social Endowment Insurance, Risk, Countermeasure

\section{Introduction}

According to the definition of the international community to aging, in a country or a region, if the population aged over 60 is more than $10 \%$ of the total, or aged over 65 is more than $7 \%$ of the population, this country or region can be regarded as an aging society. The greater proportion of elderly population shows the higher degree of the aging population.

With the development of science and technology and the improvement of medical and health, as well as people's increasingly attention to physical health, the global aging population is growing rapidly and the elderly population is growing at present. So it brings various influences to the social economic development. Many countries are facing the challenge of an aging population. Around the world, it has become a globally and strategically social problem. 
Our country has entered into the aging society as early as in 2000 [1]. The aging population background makes the endowment insurance system in China face with serious challenges; how to analyze the risks of endowment insurance in our country, and put forward effective measures to reduce risk are worthy to be studied. Based on the analysis of the current situation of China's population aging and the endowment insurance, this paper analyzes the risks of the endowment insurance country, puts forward the corresponding measures, and provides the suggestions for the development of endowment insurance system in our country.

The following content is divided into five parts. The first part is the analysis of the present situation and characteristics of the aging population in our country. The second part is the development situation and the problems of China's endowment insurance. The third part is the risk analysis of endowment insurance under the background of aging population in our country. The fourth part is the countermeasures and suggestions to reduce risks of endowment insurance. The last part is conclusion.

\section{The Present Situation and Characteristics of Population Aging in China}

China's population aging process started in the 1980s and accelerated after that. According to the fifth census figures which released by the national bureau of statistics of the People's Republic of China, as to November 1 , in 2000, the old people aged over 60 in our country has achieved to 124 million which accounts for $10.45 \%$ of the total population, and the number of elderly population aged over 65 is 88.25 million, accounting for $7.1 \%$ of the total. It shows that our country has entered into the aging society as early as in 2000 [1]. And according to the results of the sixth national population census, as to November 1, in 2010, the elderly population aged over 60 has reached 177 million which accounts for $13.26 \%$ of the total population in China, of which, the number of elderly people over 65 is about 119 million, accounting for $8.87 \%$. As you can see, our country is the only country in the world today that the number of old people is close to 200 million [2]. According to this trend, by 2025, China's aging population will reach about 284 million which accounts for $19.34 \%$ of the total population, and that will peak nearly 430 million people around the year of 2050, accounting for more than a quarter of the total.

At the same time, because of the special national conditions, population environment and traditional culture in China, it makes the population aging in our country present the following distinctive features: First, the speed of the population aging is faster than that of economic growth. Basically, developed countries step into an aging society after realizing the social modernization. But our country has entered into the aging society in advance under the condition of undeveloped economy and without achieving modernization. When developed countries entered into the aging society, per capita gross domestic product (GDP) is generally at about $\$ 5000$ to $\$ 10,000$, but when our country entered into the aging society, per capita gross domestic product (GDP) has just been over $\$ 1000$. As you can see, our country still belongs to the one of medium low income. It appears relatively weak in dealing with the aging of the population. Second, with the faster speed of aging population, and which showed a trend of accelerated, in 2000, the number of the elderly over the age of 60 is 124 million in our country, and in 2010, this number has reached 177 million. The elderly population aged over 60 has risen by more than 5000 in just ten years. According to statistics, in recent years, the speed of population aging in our country is far more quickly than Europe and the United States and other countries, even faster than Japan's. The proportion of China's elderly population (65 people aged, hereinafter the same) increased from $4.91 \%$ to $6.96 \%$, which had spent for 18 years. And it increased from 4.79\% to 7.06\% in Japan, which had spent for 20 years. And it increased from $5.2 \%$ to $8.4 \%$ in Sweden, which had spent for 40 years.

The increasing proportion of elderly population brings to the growing social economic pressures [3]. Third, it is the unbalanced regional development. Figures show that as the eastern region defined as the labor-into area, the middle-aged and young population accounts for a larger proportion. Although facing an aging population, it provides a strong backing for the endowment enterprise because of its good prospects for development and economic strength. And as the central and western regions defined as the labor-outflow areas, the elderly population deposits, especially in the vast rural areas, it formed a large number of empty nest elderly group. It contributed to the local endowment pressure with no doubts.

\section{The Development Overview and the Problems of Endowment Insurance in China}

\subsection{The Development Overview}

Our former pension system was established in 1951, it’s a typical national protection mode. Since China imple- 
mented the urban-rural split planned economic system, the endowment insurance system is a "corporate guarantee" mode, to protect the "sickness and death" of employees work in the state-owned enterprises and state government. And farmers are relying on family self-protection. With the continuous development of China's economy and society, the old endowment insurance model has been difficult to adapt to the new times. Therefore, the Chinese government proposed to gradually establish a sound social security system which adapt to the situation, and clarify the development direction of social insurance in the "economic and social development of the People's Republic of China Seventh Five-Year Plan” which issued in 1986. From so on, endowment insurance began the transition from guaranteed by the unit to guarantee by the social security.

China's current pension system was formed in the early 1990s. In 1991, the State Council issued the "Decision on Pension Reform of Enterprise Workers", it meant that the modern pension insurance system was established on the basis of social overall planning. In 1995, the State Council issued "Notification on Deepening the Reform of Endowment Insurance System for Enterprise Employees", which proposed that our social endowment insurance was a system which combined the social overall planning and personal account, and clarified the rights and obligations of endowment insurance. In 1997, the State Council issued the "Decision on the Establishment of a Unified Basic Pension Insurance System for Enterprise Workers" to further regulate the collection and payment of endowment insurance funds [4].

Meanwhile, in order to adapt to market changes and timely follow up requirements of rights protection of the public, the Chinese government promulgated "Trial Measures of Enterprise Annuity" and "Trial Measures of Enterprise Annuity Fund Management” in 2004 to further regulate the establishment, management, investment operations of enterprise annuity. In 2010, the "People’s Republic of China Social Insurance Law" was introduced, laid a more solid legal foundation for the development of social security.

With the improvement of China's endowment insurance system and the increasing number of insurance purchase, endowment insurance funds are continuously enriched. According to statistics, in the end of 2013, the number of urban workers participated in basic pension insurance reached 322.18 million, fund revenue reached 2.268 trillion yuan. At the same time, the National Social Security Fund cumulative has exceeded to 1.2 trillion yuan in 2013. In a word, China's endowment insurance industry has made great achievements in the process of continuous reform and improvement.

\subsection{The Existing Problems}

Although our country has already established the endowment insurance system of combination of all credit accumulation type in the overall. And it has played an important role in the aspect of social harmony and stability and people's livelihood welfare. But there is no denying that, because the time of our country social security system set up is shorter, there are still some problems in some system designing level and practical level, it needs to be constantly improved.

There are two main problems. First of all, it is the endowment insurance fund devaluation. Endowment insurance fund in our country mainly includes the following four parts: one is that all credit combination of town workers' basic endowment insurance fund, secondly, the urban and rural residents' basic endowment insurance fund, thirdly, it is the endowment insurance as a compensatory of enterprise annuity and occupational pension, the fourth is the national social security fund as a strategic reserve. At present, these four parts of endowment insurance fund has accumulated to hundreds million yuan. Facing such a scale of fund in stock, it is a big problem to how to carry out the effective investment operation. And in accordance with the growth trend of estimate now, in the next 30 years, China's endowment insurance fund scale will reach a giant size of hundreds of thousands of billion. In the face of such trend, if lacking of effective investment operations, the annual rate of depreciation fund losses will be extraordinarily amazing [5].

Secondly, it is how to efficiently and fairly repay "historical debt" pension to the old employees in the stateowned enterprises. Since the reform in the 1990s, because of the change in the mode of payment, tens of millions of older workers in state-owned enterprises turned the old pension system into the new endowment insurance one of all credit combination, accumulating to "historical debt" pension. This is the problem that the government must face [6]. It is the step in the process of perfecting the endowment insurance system in China that government must go in how to resolve this efficient and fair "historical debt", and to find the feasible rational solutions. Otherwise, if the problems left over by history continue to "fermentation", it may become the huge risks to block the healthy development of the old-age insurance system in our country. 


\section{Risk Analysis of Endowment Insurance under the Background of Aging Population}

Be faced up with the grim problem of aging population, China's current endowment insurance system faces the challenge of various risks. The current “overall planning and personal account system” type pension system is not perfect, there are still many risks in funding sources, system management, regulatory and other aspects of investment. With the accelerated aging of the population, these problems may arise, and new risks will emerge. Overall, the risks of endowment insurance mainly as follows.

\subsection{Economic Risks}

\subsubsection{Aging Population Has a Negative Impact on China's Economic Development}

Throughout the history of social security of the world, the establishment, the development and improvement of a social security system require a certain level of economic development as a basis. As a part of the social security, endowment insurance, of course, is not an exception, its establishment, development and improvement are based on the certain economic basis. When the social and economic turmoil leads to insufficient labor supply or inadequate capital accumulation, and aging population leads to the costs of social pension continue to rise, squeez economic development, the rigid demand characteristics of pension determine any reform for the pension insurance system will face corresponding risks. So the aging population will impact the macroeconomic, including labor supply reduction, insufficient capital accumulation, slowing the pace of development of China's economy, the lack of domestic consumer demand and other negative consequences.

\subsubsection{Aging Population Has Posed a Severe Challenge to Our Current Funding Model}

As we all know, the change of the age structure of the population of the country or region will affect the local labor supply situation. China is currently implementing an overall planning and personal account system type pension. The fund mainly comes from individuals and businesses. China is currently in the "turning point” period of demographic dividend, the supply of labor on the whole is still very abundant, which also makes relatively stable populations to pay for pension. The pension is used for workers who retired and help the fund to reach a certain extent of the balance of payments. However, due to the continuous implement of the birth control policy, as well as aging population, China’s labor supply will decrease eventually. It also means shrinking group of pension contributions, fund revenues continue to decline, while the elderly population continues to increase; it means that pension spending will continue to increase. As a result, it may lead to pension payments deficit. So, in the face of a growing aging population problem, our current financing mode of the pension system will face serious challenges.

\subsubsection{Aging Population Increased the Ratio of Support of Endowment Insurance}

The ratio of support refers to ratio of supporting elderly, the older population accounts for the proportion of working-age population, it can measured by how many elderly who need to be support by the per 100 workingage population. China's aging population means that the elderly population is growing, and along with the birth control policy, the working-age population will continue to decrease, this means that the pressure of China's working-age population to support the elderly will also become increasingly greater. Data show that, according to the saying that our country had entered the aging society in 2000, and then the ratio of support is $9.9 \%$, but now this number has been changed a lot. In 2012, the ratio of support is $20.66 \%$, by the end of 2013, this ratio rose to $21.58 \%$. As can be seen, the ratio of support is increasing year by year, the burden of the working age population support elder is increasing.

\subsubsection{Risk of Fund Investment Operations of Endowment Insurance}

The National Social Security Fund Council was founded in 2000. It is responsible for the investment operations of social security fund, and guarantees that the value of the fund could be preserved or even increased. According to statistics, the cumulative National Social Security Fund has exceeded 1.2 trillion yuan in 2013. At the same year, China's basic endowment insurance fund revenue is 2.4733 trillion yuan, of which, the total revenue of basic pension insurance fund of urban workers is 2.268 trillion yuan, the basic pension insurance fund income of urban and rural residents is 20.53 billion yuan, while the basic pension insurance fund expenditure was 1.9819 trillion yuan, the basic pension insurance fund in the end of the year accumulated 3.1275 trillion yuan. 
Moreover, China's pension insurance personal accounts have accumulated a lot of fund.

Aging population will undoubtedly raise serious challenges to the work of preserved and increased value of our pension funds. From existing investments, the investment range of pension funds is limited to bank deposits, bonds and other financial instruments traded with good liquidity, and the proportion of investment in each project is strictly controlled. Before aging problem did not come, put the pension funds in the bank or invest on non-risk and low-risk products is the best choice to ensure its security. But with the arrival of aging, how to invest on various combinations products is of important to social security funds, particularly in increasing the value of pension funds and better able to ensure their safety. Only wake the "sleeping" pension and put them to portfolio investment, the value of the pension fund could increased, thereby enabling the pension rights to be protected.

\subsection{Institutional and Policy Risks}

\subsubsection{Aging Population Highlighted the Level Issues of Endowment Insurance}

Due to the different levels of economic development in eastern, central and western regions, payment rate for each region varies, the standard of the base of payment of various regions is different; this undermined the pension funding mechanism. Therefore, how to improve the overall level of pension became the most hard event which was mentioned in every reform. At present, China's overall level of pension nominally reach the provincial level, but the actual operation level still remain in the cities and counties. The low overall level limit resource mobilization, it is difficult to alleviate the pressure to pay effectively. Therefore, the low overall level becomes an obstacle to the improvement of endowment insurance.

\subsubsection{Aging Population Caused the Retirement Policy Problems}

When faced up with challenges of aging population, improving the payment rate of the social security can be a response way. If implement this response way, when the contribution rate increase to a certain extent, the collection of pension has become a policy which is of pure tax nature. Workers will tend to choose to retire early and enjoy the endowment insurance benefits, and thus evade their obligation to pay. Throughout western countries, when fix the contribution rate, in order to make pension be able to withstand the risks of aging population, most countries basically chosen to extend the retirement age. With this approach, an increase of years for elder in the workplace can indeed raise the revenue of pensions, but at the same time, the new jobs in society is very limited, which means employment of young workers reduce. As a result, it may cause a conflict between the groups of different age and impact the social harmony.

\section{Suggestions to Deal with the Risk of Endowment Insurance}

\subsection{Establishment of Long-Term Mechanism to Prevent the Risk of Endowment Insurance System}

In the process of establishment and reform of the pension system, western developed countries usually legislate first and then start pension reform according to the law. It is advanced experience which be worthy of learning. Therefore, to improve the legal system which is closely related to the social endowment insurance system arrangements is a long-term fundamental countermeasures to prevent the risk of pension. In recent years, China has introduced the relevant legal provisions "Interim Measures of the basic pension insurance relationship transform of urban enterprise workers", "Social Insurance Law", laid the general framework for the development of pension insurance. The priority is to deal with the increasing aging population, introduce more specific, feasibility laws and regulations, strengthen the legal support of the operation of pension system.

\subsection{Broaden Funding Channels of Endowment Insurance to Establish a Multi-Level Pension System}

First, as a part of the social pension insurance, pension is of social characteristics, so it should cover all workers as much as possible in its process of implementation, and thus broaden the pension funding sources to increase pension income. Second, improve our three-pillar pension system. National basic pension is the first pillar, its status and role should be further strengthened and consolidated. Enterprise supplementary pension insurance is the second pillar, its current development is not ideal, need the support of national policies. Individual savings 
pension is the third pillar, which is supplementary pension schemes on a personal level. Individual savings pension has only a little development, so it needs the attention and guidance of government. Finally, try to carry out commercial pension insurance. As the extent of the aging of our population continues to deepen, pension issues cause more and more attention. Because social endowment insurance only provides basic security, so it's liable to supply commercial pension insurance in the eastern region, and encourage the qualified elderly to buy it. At last realise the positive effect of business pension insurance in the social security system.

\subsection{Strengthen Supervision to Preserve and Increase the Value of Endowment Insurance Funds}

The primary principle of pension fund investments is safety. Therefore, the government needs not only to develop appropriate policies and regulations to the operation of pension fund, to guide the operation of fund investment management, but also clear the responsibility authority of investment company, to prevent and resolve operational risk and ensure that the risk of investment project could minimum. Besides, it's essential to give some short-term financing facility to pension funds. For example, to allow pension funds into the interbank market and the bond market to participate in repurchase transactions. This will not only enhance the flowability of the fund, but also help to manage asset more actively. In short, only guarantee the security, the realization of the increasing value of pension funds has a practical significance.

\subsection{Relax the Birth Control Policy and Extend the Retirement Age}

The degree of aging population of our country continues to deepen, the elderly population continues to increase and this leads to the reduction of the working-age population. In such case, relax the one-child policy, allowing some eligible families a second child, increasing population, thereby ensuring the subsequent supply of labor force. At the same time, our country is still follow the old retirement system which was established in the last century, that male workers retired in 60-year-old, female workers retired in 50-year-old, the retirement age of female cadres is 55. And with the development of society, advances in medical technology, the average lifetime has been significantly extended. Therefore, the old retirement system has been difficult to adapt to China's current economic and demographic structures. Throughout the world, the statutory retirement age of all developed countries and even many developing countries are higher than China. Extend the retirement age can increase pension income and reduce pension spending, to leave enough time for pension fund to respond to payment risk.

\section{Conclusion}

Based on the analysis of the current situation of China's population aging and the endowment insurance, this paper analyzed the risk of endowment insurance of China under the background of population aging. On the one hand, the current "overall planning and personal account system” type pension system is not perfect, and due to the acceleration of population aging, China's endowment insurance fund will face with financing and investment risks, which may cause negative effect on the development of the economy. On the other hand, an ageing population will lead to retirement problems, and highlight the level issues of China's endowment insurance. So, this paper put forward four solutions, including legislation, broadening the financing channels of endowment insurance, preserving and increasing the value of endowment insurance funds and extending the retirement age, etc. This will help reduce the risks of endowment insurance, and promote the development of the endowment insurance in China.

\section{References}

[1] The People’s Republic of China National Bureau of Statistics (2001) Fifth Census Data Bulletin People’s Republic of China.

[2] The People’s Republic of China National Bureau of Statistics (2011) Sixth Census Data bulletin People’s Republic of China.

[3] Yuan, W. and Cong, R. (2010) The Impact of Aging Population Trend on China's Pension Insurance System and Countermeasures. Business Culture: Academic Edition.

[4] Luan, S.S. (2011) Thinking for Population Aging on the Pension System. Management, 19, 108. 
[5] Zheng, G.C. (2002) The Development of China’s Social Security System and Assessment. Press of Renmin University of China, Beijing.

[6] Le, X.M. and Wu, X.Y. (2008) Estimated Pension Personal Accounts Affected by Inflation Risks. Statistics and Decision, 11, 66-68. 